\title{
ARTICLE
}

Cite this: DOI: 10.1039/x0xx00000x

\section{Structural variations in metal complexes of a tertiary $\alpha$-hydroxyoxime}

\author{
Daniel D'Alessio, ${ }^{a}$ Daniel M. Lombardo, ${ }^{a}$ Jamila G. Vaughan, ${ }^{a}$ Brian W. \\ Skelton, ${ }^{b}$ Keith R. Barnard ${ }^{c}$ and Mark. I. Ogden ${ }^{*} a$
}

Received 00th January 2012 Accepted 00th January 2012

DOI: $10.1039 / \times 0 \times x 00000 x$

www.rsc.org/

\begin{abstract}
Despite the long term interest in hydroxyoximes as metal ion extractants, there is a lack of information on the possible coordination modes these ligands can assume, particularly in concert with a co-ligand. This is pertinent to the use of these extractants in synergistic systems, where a combination of extractants can achieve commercially useful results. We report here the structures of some metal complexes $(\mathrm{M}=\mathrm{Mn}, \mathrm{Co}, \mathrm{Ni}, \mathrm{Cu}$, and $\mathrm{Zn})$ with (1hydroxycyclohexyl)-phenyl ketone oxime. The results demonstrate that this ligand can support complexes ranging from mononuclear to trinuclear, in association with anionic and neutral co-ligands in some cases. While these results have been obtained in the solid state, they illustrate a range of possible species that may be formed in extractant solutions.
\end{abstract}

\section{Introduction}

Hydroxyoximes have been used in solvent extraction (SX) processes on an industrial scale for decades. Despite this history, there is a need to improve the effectiveness of SX processes, to face the challenges of declining ore quality, and the complications of extracting metals from recycled materials. ${ }^{1}$ One approach towards improving SX systems is to exploit combinations of extractants that act as synergistic systems, where the performance of the mixture exceeds that of the individual components. One such mixture is the combination of LIX 63 (containing the aliphatic $\alpha$-hydroxyoxime 5,8-diethyl7-hydroxydodecan-6-oxime) with various organic acids, particularly the carboxylic acid extractant Versatic $10 .^{2}$ While this synergistic system is currently being implemented for commercial use $^{3}$ challenges remain. For example, the secondary hydroxyl group in LIX 63 provides a pathway to oxidative degradation of the extractant, ${ }^{4}$ which impacts on the economics of the process. ${ }^{4 a, 5} \mathrm{We}$ have recently demonstrated that a tertiary reagent, (1-hydroxycyclohexyl)-phenyl ketone oxime, $\mathbf{L}$, resists oxidative degradation while maintaining synergistic SX behaviour with Versatic $10 .{ }^{6}$ Thus, we are interested in how the $\alpha$-hydroxyoxime $\mathbf{L}$ interacts with metal cations, especially in combination with other ligands. Relatively few $\alpha$-hydroxyoxime metal complexes have been structurally characterised, which is somewhat surprising given the industrial relevance of this class of ligand. $\alpha$-Benzoin oxime has been reported to support the formation of some spectacular "molecular wheels" and coordination polymers with copper and nickel. ${ }^{7}$ Some oligomeric manganese complexes of $\alpha$-hydroxy oximes with interesting magnetic properties have also been reported. ${ }^{8}$ We have reported mononuclear complexes of nickel and cobalt with a C8 analogue of LIX $63 .^{3,9}$ No metal complexes of $\mathbf{L}$ have been reported to date. Here we report the structural characterisation of complexes of $\mathbf{L}$, with manganese(II, IV), cobalt(II), nickel(II), copper(II) and zinc(II), in the presence of neutral and anionic co-ligands. The complexes range from mononuclear to trinuclear, and indicate that complex mixtures may be present in an industrial solvent extraction process utilising such a ligand as a metal extractant.<smiles>O/N=C(\c1ccccc1)C1(O)CCCCC1</smiles>

\section{Experimental}

\section{Syntheses}

All manipulations were performed under aerobic conditions, and reagents and solvents were used as received. The ligand (1hydroxycyclohexyl)-phenyl ketone oxime, L, was synthesised as reported previously. ${ }^{6}$ Crystals of $\mathbf{L}$ suitable for a single crystal structure determination were obtained by diffusing ether into a solution of $\mathbf{L}$ in ethyl acetate. 
$\left[\mathrm{NiL}_{2}\left(\mathrm{OH}_{2}\right)\left(\mathrm{ONO}_{2}\right)\right] \mathrm{NO}_{3}$, (NiL). Nickel(II) nitrate hexahydrate $(51 \mathrm{mg}, 0.175 \mathrm{mmol})$ was suspended in ethyl acetate $(30 \mathrm{~mL})$ and sonicated for 10 minutes. Oxime $\mathbf{L}(114 \mathrm{mg}, 0.52 \mathrm{mmol})$ was then added and the solution sonicated for an additional 10 minutes. The slightly cloudy solution was filtered and allowed to stand and evaporate, forming crystals suitable for single crystal X-ray structure determination.

$\left[\mathrm{ZnL}_{2}\left(\mathrm{OH}_{2}\right)\left(\mathrm{ONO}_{2}\right)\right] \mathrm{NO}_{3},(\mathbf{Z n L})$. The same procedure used for NiL was followed, substituting zinc(II) nitrate hexahydrate for the nickel salt.

$\left[\mathrm{MnL}_{2}\left(\mathrm{OH}_{2}\right)\left(\mathrm{ONO}_{2}\right)_{2}\right]$, (MnL). The same procedure used for NiL was followed, substituting manganese(II) nitrate tetrahydrate for the nickel salt.

[CuL $\left.2\{\mathrm{OPPh}(\mathrm{O})(\mathrm{OH})\}_{2}\right], \quad(\mathbf{C u L}) . \quad$ Phenylphosphinic acid (20 mg, $0.14 \mathrm{mmol}$ ) dissolved in $0.8 \mathrm{~mL}$ of 99:1 ethyl acetate:methanol was added to $\mathrm{Cu}\left(\mathrm{NO}_{3}\right)_{2} .2 .5 \mathrm{H}_{2} \mathrm{O}(0.0183 \mathrm{~g}$, $0.079 \mathrm{mmol})$ in hexanes $(4.5 \mathrm{~mL})$ and the mixture was sonicated for 20 minutes. Triethylamine $(19.5 \mu \mathrm{L}, 0.14 \mathrm{mmol})$ was added to the solution and it was sonicated for a further 20 minutes. A solution of the oxime $\mathbf{L}(0.10 \mathrm{~g}, 0.45 \mathrm{mmol})$ in ethyl acetate $(2.5 \mathrm{~mL})$ was added and the mixture sonicated for 20 minutes. The solution was then left to slowly evaporate and afforded small blue crystals of $\mathbf{C u L}$ suitable for single crystal $\mathrm{X}$-ray structure determination.

$\left[\left\{\mathrm{CuL}_{2}\left(\mathrm{OSO}_{3}\right)\right\}_{2}\right] .\left(\mathrm{C}_{4} \mathrm{H}_{8} \mathrm{O}_{2}\right), \mathbf{C u} 2 \mathbf{L}$. The same procedure used for NiL was followed, substituting copper(II) sulfate pentahydrate for the nickel salt.

$\left[\mathrm{Mn}_{3}(\mathbf{L}-2 \mathrm{H})_{6}\right] \cdot 0.5 \mathrm{H}_{2} \mathrm{O}$, Mn3L. The same procedure used for MnL was followed, except triethylamine $(0.43 \mathrm{mmol})$ was added to the final solution. Dark purple crystals of Mn3L were deposited on standing.

$\left[\mathrm{Co}_{3}(\mathbf{L}-\mathrm{H})_{4}\left(\mathrm{O}_{2} \mathrm{CC}_{3} \mathrm{H}_{7}\right)_{2}\right], \mathbf{C o 3} \mathbf{L}$. Cobalt(II) nitrate hexahydrate (52 mg, $0.177 \mathrm{mmol}$ ) was partially dissolved into a solution of iso-butyric acid $(39.8 \mu \mathrm{l}, 0.43 \mathrm{mmol})$ in ethyl acetate $(30 \mathrm{~mL})$. After 10 minutes of sonication, the oxime $\mathbf{L}(114 \mathrm{mg}, 0.52$ mmol) was added to the solution and sonication continued for a further 10 minutes. The slightly cloudy solution was filtered and left to evaporate, resulting in the formation of crystals suitable for X-ray analysis.

\section{Crystallography}

Crystallographic data for the structures were collected at 100(2) $\mathrm{K}(150(2) \mathrm{K}$ for $\mathbf{C u L})$ on an Oxford Diffraction Xcalibur or Gemini diffractometer fitted with Mo K $\alpha$ radiation. Following analytical or multi-scan absorption corrections and solution by direct methods, the structures were refined against $F^{2}$ with fullmatrix least-squares using the program SHELXL-97. ${ }^{10}$ Anisotropic displacement parameters were employed for all the non-hydrogen atoms with hydrogen atoms refined by use of a riding model with isotropic displacement parameters based on those of the parent atoms unless otherwise stated. Results are given in Table 1 and in Figures 1-7. In Figures 2-7 non-C atoms are drawn with $50 \%$ probability amplitude displacement ellipsoids with hydrogen atoms being omitted. $\mathrm{OH}$ hydrogen atoms have been included as spheres of arbitrary radii. All $\mathrm{H}$ atoms have been included in Figure 1. Full details of the structure determination have been deposited with the Cambridge Crystallographic Data Centre with deposit numbers included in Table 1. Copies of this information may be obtained free of charge from The Director, CCDC, 12 Union Road, Cambridge CB2 1EZ, UK (Fax: + 441223336 033; e-mail: deposit@ccdc.cam.ac.uk or www: http://www.ccdc.cam.ac.uk). For L, MnL and CuL, O-H distances were refined without restraints. For NiL, ZnL and Cu2L, O-H distances were restrained to ideal values. For Mn3L, the site occupancy of the solvent water molecule refined to $0.541(16)$. The accompanying hydrogen atoms were not located. For Co3L, the phenyl ring of one oxime ligand and several atoms of the coordinated iso-butyrate ligand were modelled as being disordered over two sets of sites with occupancies set at 0.5 after trial refinement. Residual electron density was effectively removed by use of the program SQUEEZE. A hydrogen atom located on O121 was refined with geometries restrained to ideal values. The hydrogen atom assumed to be on $\mathrm{O} 2$ was not located.

\section{Results and Discussion}

Crystals of the ligand $\mathbf{L}$ were obtained by diffusing ether into an ethyl acetate solution. The structural characterisation showed that the molecule was present as the anti isomer, consistent with previous reports. ${ }^{6}$ There are two independent molecules per asymmetric unit. These are hydrogen bonded through the $\mathrm{NOH}$ groups to form a hydrogen bonded dimer as shown in Fig.1(a). There are further hydrogen bonds between the hydroxyl hydrogen atoms of both molecules to the molecules of the dimer related by an inversion centre thus forming a hydrogen bonded tetramer (Fig. 1(b)). 


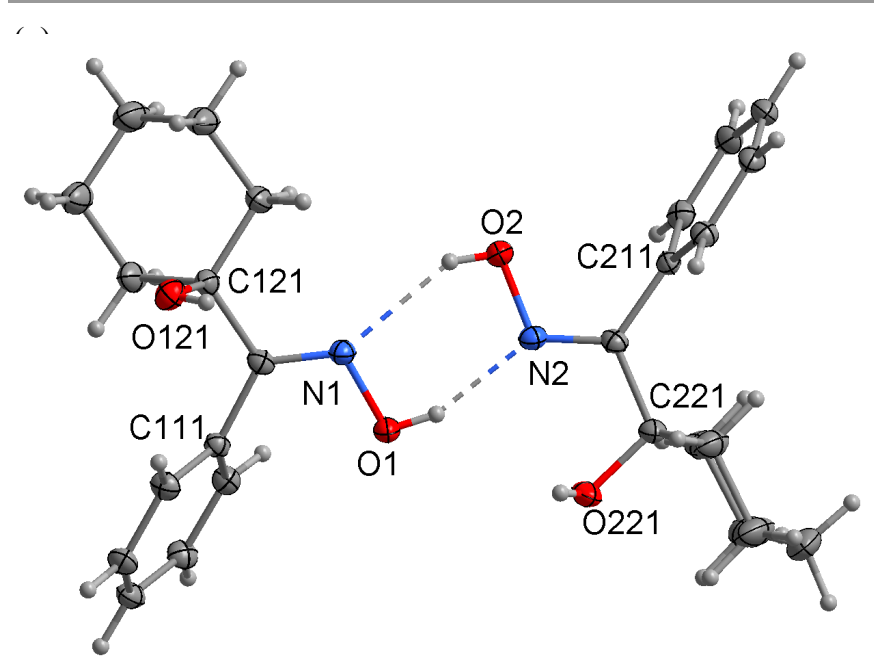

(b)

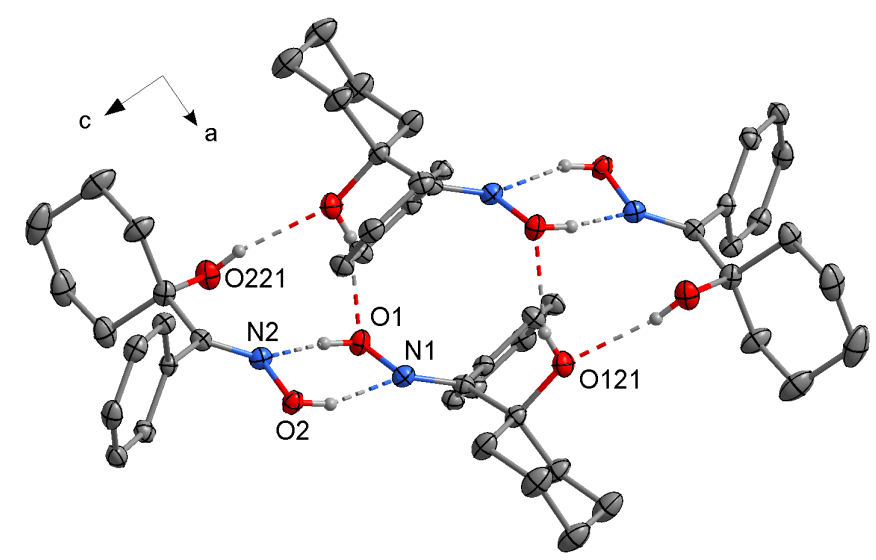

Figure 1. (a) Structure of the hydrogen bonded dimer of $\mathbf{L}$ projected onto the $\mathrm{N}_{2} \mathrm{O}_{2}$ plane of the dimer. (b) Structure of the hydrogen bonded tetramer of $\mathbf{L}$ projected along the $b$-axis.

Combining the hydroxyoxime $\mathbf{L}$ with nickel(II), and zinc(II) nitrates resulted in the crystallisation of isomorphous monomeric 6-coordinate complexes. The coordination spheres include two bidentate neutral hydroxyoxime ligands, disposed in a cis configuration (Figure 2). The remaining two coordination sites are occupied by two unidentate ligands, one nitrate anion and one water molecule $(\mathrm{Ni}, \mathrm{Zn})$. There is an intra-molecular hydrogen bond between $\mathrm{H} 1$ on the $\mathrm{NOH}$ of one oxime ligand to the coordinated nitrate oxygen atom. There are also hydrogen bonds from the coordinated water molecule (H10A), and the hydroxyl group $\mathrm{OH}(121)$, to the uncoordinated nitrate. The hydrogen on the NOH group of the remaining oxime, $\mathrm{H} 2$, and the remaining water molecule hydrogen atom, $\mathrm{H} 10 \mathrm{~B}$, both form hydrogen bonds to the uncoordinated nitrate anion related by a crystallographic inversion creating a hydrogen-bonded dimer (Figure S1). The remaining hydroxyl hydrogen atom, H221, also forms hydrogen bonds to a centrosymmetrically related uncoordinated nitrate anion but one which is transformed by a cell translation in the $c$ direction, thus forming a one-dimensional hydrogen bonded polymer (Figure S1).

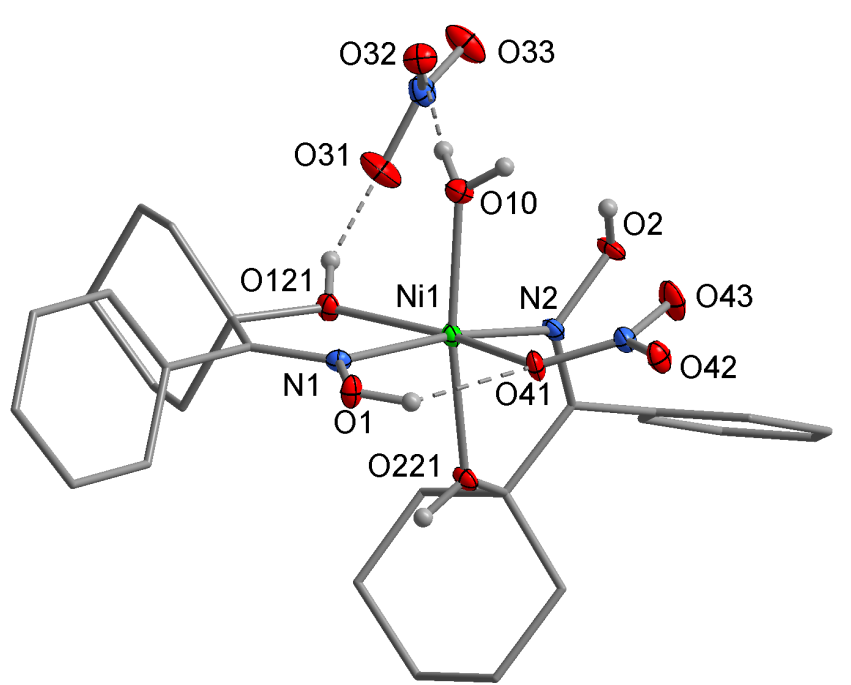

Figure 2. The complex cation found in NiL, and nitrate anion linked by a hydrogen bond between $\mathrm{O} 10$ and $\mathrm{O} 32$.

The analogous $\mathrm{Mn}(\mathrm{II})$ complex, $\mathbf{M n L}$, is similar to the $\mathrm{Ni}$ and $\mathrm{Zn}$ complexes, but is essentially 7-coordinate with both nitrate anions coordinated, one being asymmetric bidentate and the other unidentate (Figure 3). There are intramolecular hydrogen bonds between each of the $\mathrm{NOH}$ hydrogen atoms and a coordinated oxygen atom of each of the nitrate groups. Intermolecular hydrogen bonding is observed between the hydroxyl hydrogen atoms and the uncoordinated nitrate oxygen atoms of the molecules related by inversion centres again forming a one dimensional hydrogen bonded polymer (Figure S2). 


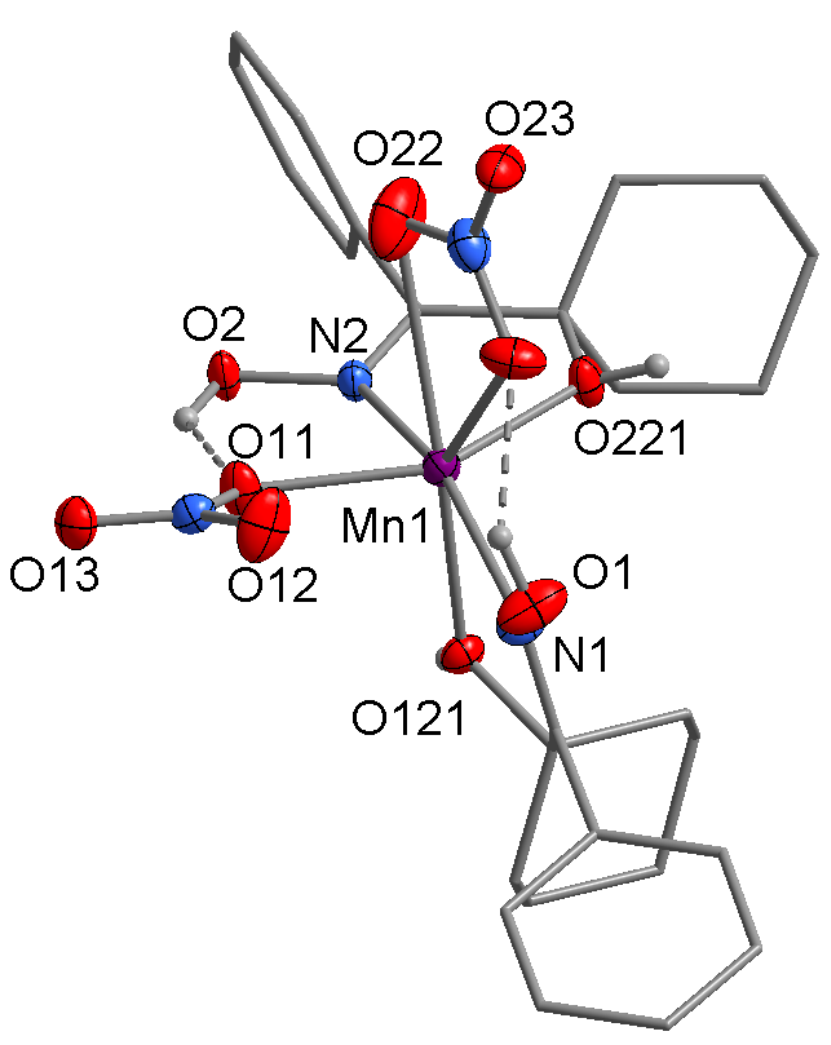

Figure 3. Structure of the molecule of $\mathrm{MnL}$ showing the intramolecular hydrogen bonding.

While no appropriately crystalline product was obtained with copper(II) nitrate alone, addition of phenylphosphinic acid resulted in the crystallisation of $\mathbf{C u L}$. The complex structure was found to be similar to those already discussed, with two bidentate $\mathbf{L}$ ligands, and two unidentate phenylphosphonato ligands, bound to the metal atom. The phosphonato ligands presumably result from oxidation of the phenylphosphinic acid during the crystallisation process. There are two independent molecules in the asymmetric unit. Figure 4 shows molecule 1 and 2 in similar projections. The two molecules are pseudorelated by a translation of half the $c$ axis (i.e. $z+1 / 2$ ) (Figure. $\mathrm{S} 3)$. The coordination around the $\mathrm{Cu}$ atoms in the two molecules is quite different. The Jahn-Teller distortion in molecule 2 is much greater $(\mathrm{Cu}(2)-\mathrm{O}(421) 2.3609, \mathrm{Cu}(2)-\mathrm{O}(31)$ 2.5361(18) $\AA$ ) than in molecule 1, where the corresponding trans bond lengths are $(\mathrm{Cu}(1)-\mathrm{O}(221) 2.185(2), \mathrm{Cu}(1)-\mathrm{O}(11)$ 2.1113(16) $\AA$ and $\mathrm{Cu}(1)-\mathrm{O}(121) \quad 2.2375(18), \quad \mathrm{Cu}(1)-\mathrm{O}(21)$ 2.1674(17) $\AA$ ). This phenomenon has been observed previously, ${ }^{11}$ and may be the result of static/dynamic disorder of two distortions in molecule 1, whereas only one distortion is observed in molecule 2 . (a)

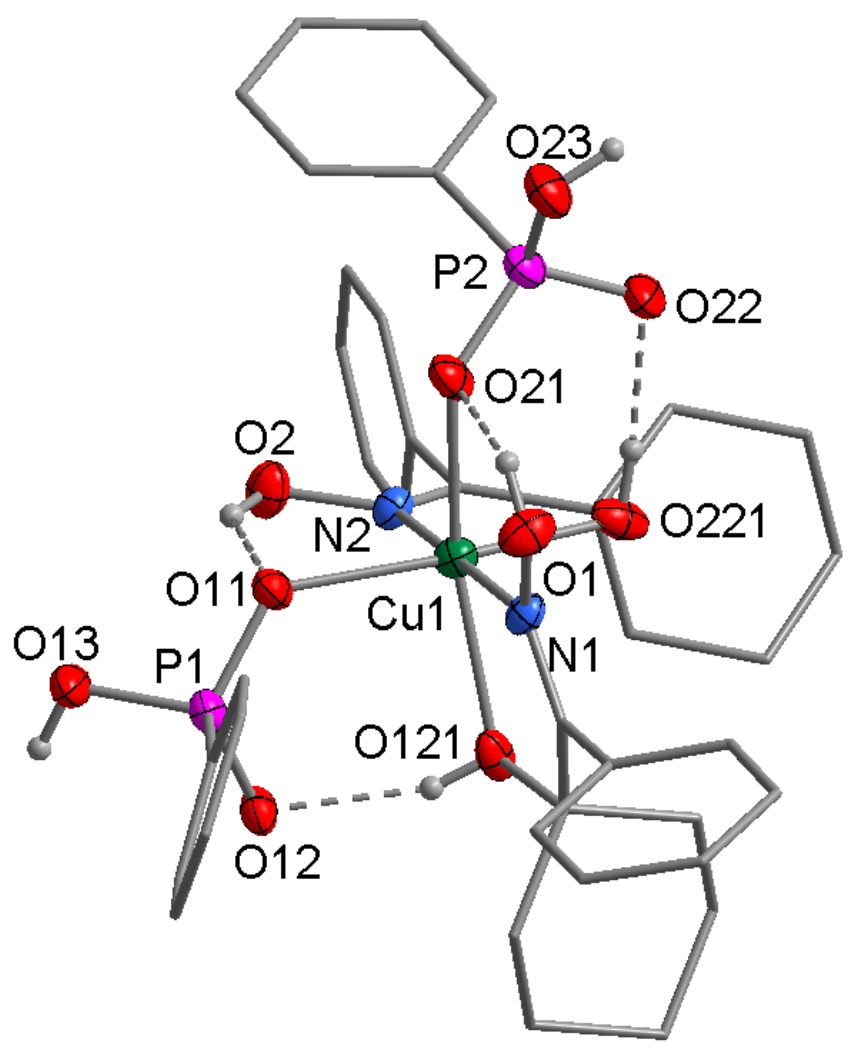

(b)

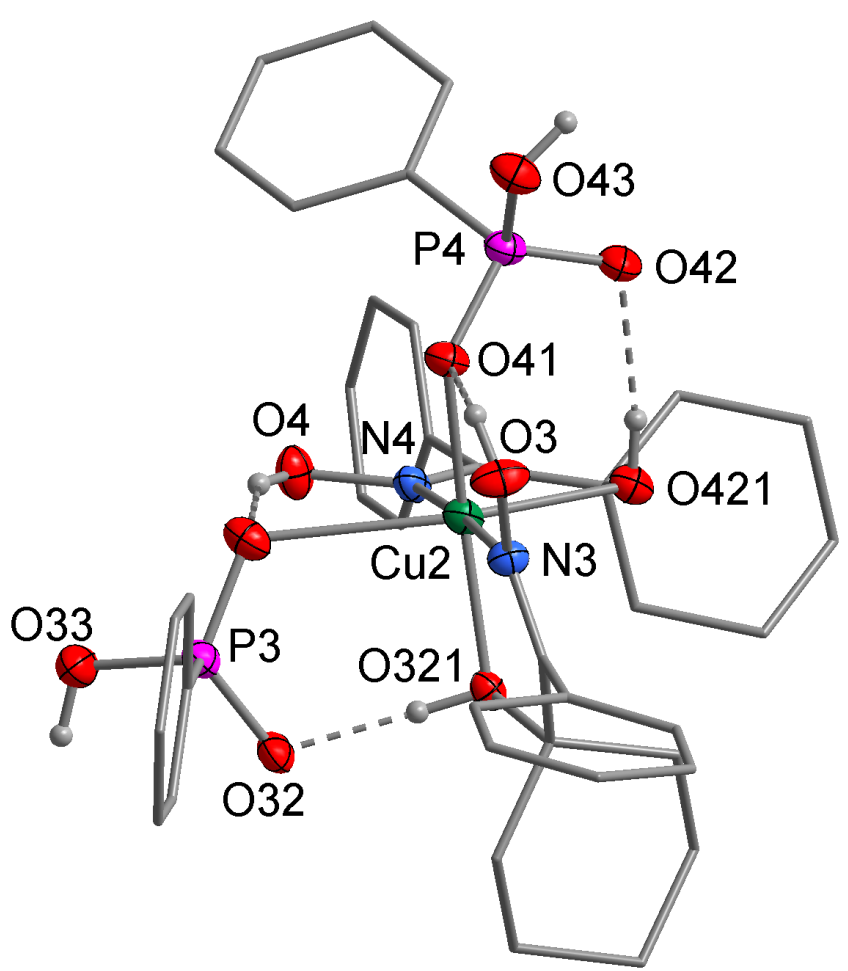

Figure 4. The two independent molecules found in the structure CuL. 
The intramolecular hydrogen bonding is similar in both molecules where $\mathrm{OH}$ and $\mathrm{NOH}$ hydrogen atoms interact with oxygen atoms of neighbouring hydrogen phenylphosphonato ligands. The $\mathrm{OH}$ hydrogen atoms of both hydrogen phenylphosphonato ligands on both molecules form further hydrogen bonds to centrosymmetrically related molecules in the $b$ direction forming a one-dimensional hydrogen bonded polymer parallel to the $b$ axis (Figure S4).

The reaction of copper(II) sulfate with $\mathbf{L}$ resulted in the crystallisation of a dimeric species, $\mathrm{Cu} 2 \mathbf{L}$, formulated as $\mathrm{Cu}_{2}(\mathbf{L})_{4}\left(\mathrm{SO}_{4}\right)_{2}$, solvated by one ethyl acetate molecule. The molecule consists of a dimer of $\mathrm{Cu}(\mathbf{L})_{2}\left(\mathrm{OSO}_{3}\right)$ units linked by weaker $\mathrm{Cu}-\mathrm{O}$ bonds to bridging sulfate groups. The two halves of the molecule are related by a pseudo 2-fold axis perpendicular to the $\mathrm{Cu}_{2} \mathrm{O}_{2}$ plane. The molecule is further stabilised by intra-molecular hydrogen bonds from the $\mathrm{NOH}$ and hydroxyl hydrogen atoms to each of the oxygen atoms of the bridging sulfate groups (Figure 5).

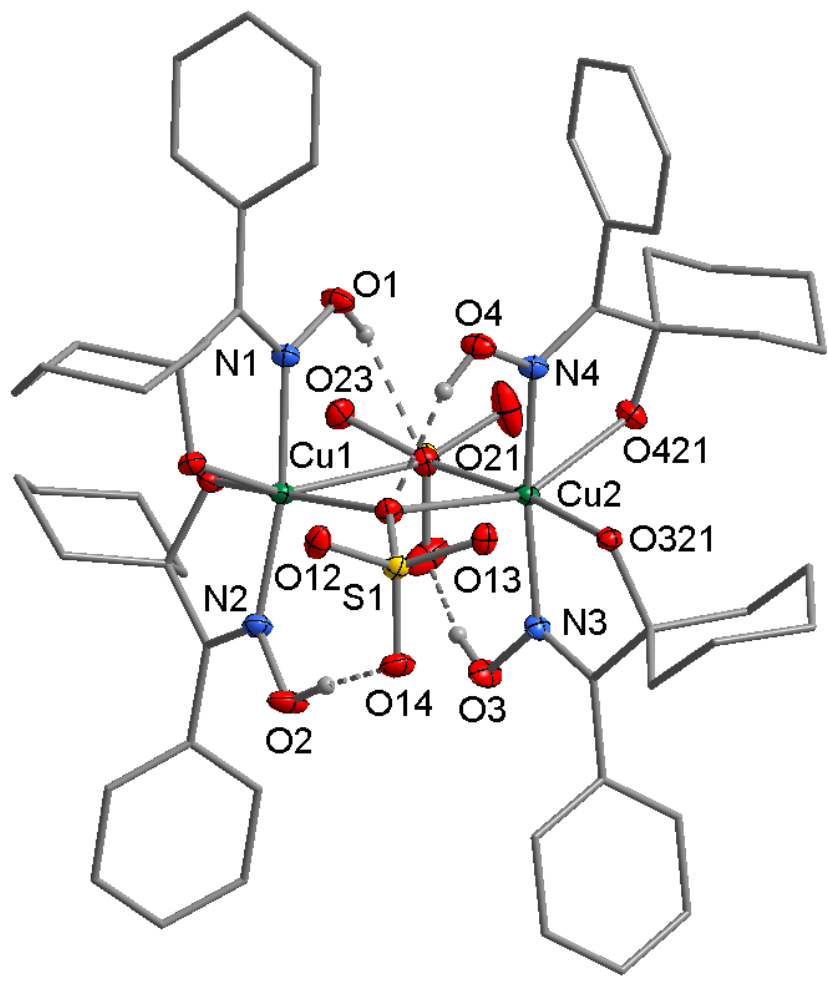

Figure 5. The dimeric structure of Cu2L.

Reaction of $\mathbf{L}$ with manganese(II) nitrate in the presence of triethylamine resulted in the crystallisation of intensely coloured purple crystals of Mn3L. The results of the structure determination were consistent with a formulation of $\mathrm{Mn}_{3}(\mathbf{L}-$ $2 \mathrm{H})_{6}$, where the manganese(II) cations have oxidised to manganese(IV), and the hydroxyl and oxime $\mathrm{O}$ atoms of $\mathbf{L}$ are deprotonated. The central atom $\mathrm{Mn}(1)$ is situated on a $\overline{3}$ crystallographic centre and coordinates to the six $\mathrm{N}$ atoms, the coordination sphere being a slightly distorted octahedron. The 'outer' $\mathrm{Mn}$ atoms bond to the oxygen atoms of the three hydroxy groups and three oxime $\mathrm{N}$ atoms forming a more distorted octahedron (Figure 6). The structure is very similar to that obtained with 1-hydroxy-1,1-diphenylpropan-2-one oxime (dpo) under similar conditions. ${ }^{8 b}$

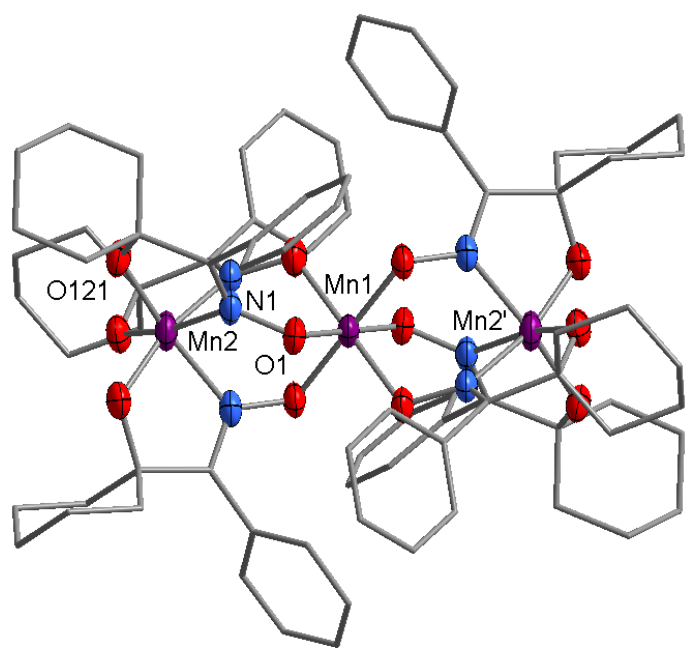

Figure 6 . Structure of the molecule of Mn3L. The prime refers to the atom at 4/3$x, 2 / 3-y, 5 / 3-z$.

The addition of $\mathbf{L}$ to a combination of cobalt(II) nitrate and isobutyric acid resulted in the crystallisation of a trinuclear complex, formulated as $\left[\mathrm{Co}_{3}(\mathbf{L}-\mathrm{H})_{4}\left(\mathrm{O}_{2} \mathrm{CC}_{3} \mathrm{H}_{7}\right)_{2}\right]$ (Figure 7). The coordination about the central $\mathrm{Co}$ atom is octahedral, with an $\mathrm{N}_{2} \mathrm{O}_{4}$ set of donor atoms, whereas the other Co atoms is 5coordinate, $\mathrm{NO}_{4}$. The Co atoms are bridged by two oxime moieties and one hydroxy $\mathrm{O}$ atom. While the specific protonation states of the ligands are rendered somewhat uncertain by the disorder in the structure, this appears to be the first example of a polynuclear cobalt complex supported by an $\alpha$-hydroxyoxime ligand.

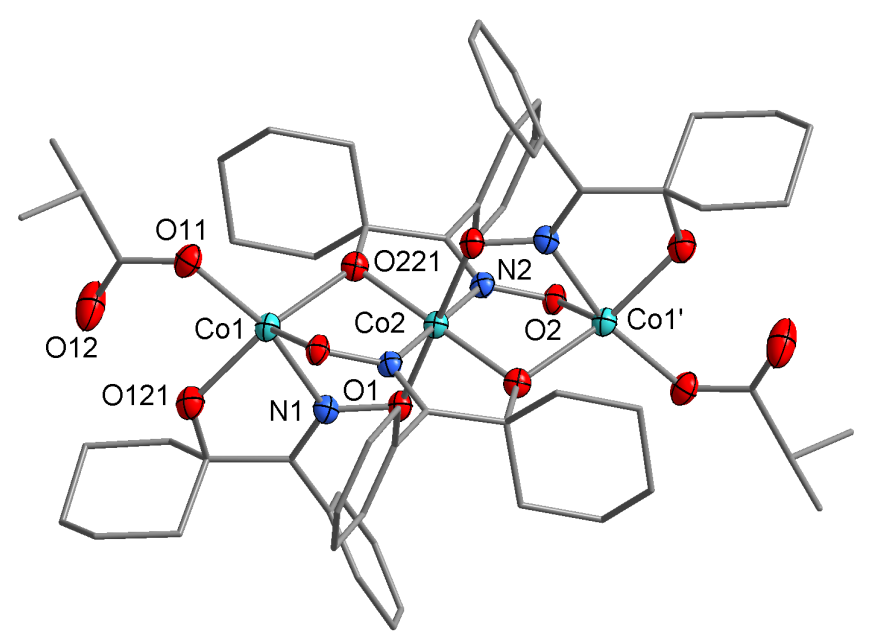

Figure 7. The molecular structure of Co3L. The prime refers to the atom at 1-x,1$y, 1-z$ 


\section{Conclusions}

It has been shown that the coordination chemistry of $\alpha$ hydroxyoxime ligands is versatile, and allows the coordination of secondary ligands to a number of transition element cations. Consistent with previous work using related ligands, polynuclear complexes can be supported by these ligands under appropriate conditions, bridged by the oxime or hydroxyl moieties. Polynuclear systems can also be formed by bridging co-ligands (sulfate anions in the example here). A common feature of these complexes is the extensive intramolecular $\mathrm{H}$ bond interactions, such that the oxime ligands are involved in both the first and second coordination spheres of the metal ion. ${ }^{12}$ These interactions are likely to stabilise the complexes formed and may have a significant impact on the solution phase speciation. ${ }^{13}$ Work is underway to examine the behaviour of $\alpha$ hydroxyoxime ligands with varying alkyl and aromatic substituents, to probe the impact on both intra- and intermolecular hydrogen bond formation in these complexes. Overall, the results suggest that industrial liquors based on these types of synergistic extractant mixtures are likely to be comprised of a complex array of coordination complexes.

\section{Acknowledgements}

The AJ Parker Cooperative Research Centre for Integrated Hydrometallurgy Solutions and CSIRO Mineral Resources Flagship are acknowledged for funding. We acknowledge use of the facilities and scientific and technical assistance of the Australian Microscopy and Microanalysis Research Facility at the Centre for Microscopy, Characterisation, and Analysis, The University of Western Australia, a facility funded by the University, State and Commonwealth Governments.

\section{Notes and references}

${ }^{a}$ Department of Chemistry, Curtin University, GPO Box U1987, Perth, Western Australia 6845, Australia

${ }^{b}$ Centre for Microscopy, Characterisation and Analysis, M313, University of Western Australia, Perth, Western Australia 6009,

Australia

${ }^{c}$ CSIRO Mineral Resources National Research Flagship, PO Box 7229, Karawara, Western Australia 6152, Australia.

Electronic Supplementary Information (ESI) available: crystal packing figures, IR spectra of metal complexes. See DOI: 10.1039/b000000x/

1. A. M. Wilson, P. J. Bailey, P. A. Tasker, J. R. Turkington, R. A. Grant and J. B. Love, Chem. Soc. Rev., 2014, 43, 123-134.
2. C. Y. Cheng, K. R. Barnard, W. S. Zhang and D. J. Robinson, Solvent Extr. Ion Exch., 2011, 29, 719-754.

3. K. R. Barnard, D. W. Shiers, M. J. McIldowie, B. W. Skelton, M. I. Ogden and T. M. McCoy, Ind. Eng. Chem. Res., 2014, 53, 82088214.

4. (a) K. R. Barnard and M. N. Tsuntsaeva, Solvent Extr. Ion Exch., 2013, 31, 79-94; (b) K. R. Barnard, N. L. Turner and D. W. Shiers, Hydrometallurgy, 2010, 104, 268-277.

5. K. R. Barnard, N. J. Kelly, D. W. Shiers, T. M. McCoy, D. L. Jones and K. E. Mayhew, Solvent Extr. Ion Exch., 2014, 32, 95-110.

6. K. R. Barnard, D. W. Shiers, N. J. Kelly and D. Lombardo, Solvent Extr. Ion Exch., 2014, in press, DOI: 10.1080/07366299.07362014.07985916.

7. (a) T. C. Stamatatos, G. Vlahopoulou, C. P. Raptopoulou, V. Psycharis, A. Escuer, G. Christou and S. P. Perlepes, Eur. J. Inorg. Chem., 2012, 3121-3131; (b) G. C. Vlahopoulou, T. C. Stamatatos, V. Psycharis, S. P. Perlepes and G. Christou, Dalton Trans., 2009, 3646-3649; (c) G. Karotsis, C. Stoumpos, A. Collins, F. White, S. Parsons, A. M. Z. Slawin, G. S. Papaefstathiou and E. K. Brechin, Dalton Trans., 2009, 3388-3390.

8. (a) F. Habib, G. Brunet, F. Loiseau, T. Pathmalingam, T. J. Burchell, A. M. Beauchemin, W. Wernsdorfer, R. Clerac and M. Murugesu, Inorg. Chem., 2013, 52, 1296-1303; (b) T. Pathmalingam, S. I. Gorelsky, T. J. Burchell, A. C. Bedard, A. M. Beauchemin, R. Clerac and M. Murugesu, Chem. Commun., 2008, 2782-2784; (c) A. G. Flamourakis, D. Tzimopoulos, M. Siczek, T. Lis, J. R. O'Brien, P. D. Akrivos and C. J. Milios, Dalton Trans., 2011, 40, 11371-11373.

9. (a) K. R. Barnard, M. Mclldowie, G. L. Nealon, M. I. Ogden and B. W. Skelton, in Proceedings of 19th International Solvent Extraction Conference ISEC 11, eds. L. F. Valenzuela and B. A. Moyer, Gecamin Ltda, Santiago, Chile, 2011, p. 161; (b) K. R. Barnard, G. L. Nealon, M. I. Ogden and B. W. Skelton, Solvent Extr. Ion Exch., 2010, 28, 778-792.

10. G. M. Sheldrick, Acta Crystallogr. Sect. A, 2008, 64, 112-122.

11. J. D. Crane, O. D. Fox and E. Sinn, J. Chem. Soc., Dalton Trans., 1999, 1461-1465.

12. (a) J. E. Kickham and S. J. Loeb, Inorg. Chem., 1995, 34, 5656-5665; (b) P. D. Beer, M. G. B. Drew and M. I. Ogden, J. Chem. Soc., Dalton Trans., 1997, 1489-1491; (c) D. J. Mercer and S. J. Loeb, Chem. Soc. Rev., 2010, 39, 3612-3620.

13. J. R. Turkington, P. J. Bailey, J. B. Love, A. M. Wilson and P. A. Tasker, Chem. Commun., 2013, 49, 1891-1899. 
Table 1. Crystal data and refinement details.

\begin{tabular}{|c|c|c|c|c|c|c|c|c|}
\hline Complex & $\mathbf{L}$ & NiL & $\mathbf{Z n L}$ & MnL & CuL & $\mathrm{Cu} 2 \mathrm{~L}$ & Mn3L & Co3L \\
\hline Formula & $\mathrm{C}_{13} \mathrm{H}_{17} \mathrm{NO}_{2}$ & $\mathrm{C}_{26} \mathrm{H}_{36} \mathrm{~N}_{4} \mathrm{NiO}_{11}$ & $\mathrm{C}_{26} \mathrm{H}_{36} \mathrm{~N}_{4} \mathrm{O}_{11} \mathrm{Zn}$ & $\begin{array}{l}\mathrm{C}_{26} \mathrm{H}_{34} \mathrm{MnN}_{4} \\
\mathrm{O}_{10}\end{array}$ & $\begin{array}{l}\mathrm{C}_{38} \mathrm{H}_{46} \mathrm{CuN}_{2} \mathrm{O}_{10} \\
\mathrm{P}_{2}\end{array}$ & $\begin{array}{l}\mathrm{C}_{56} \mathrm{H}_{76} \mathrm{Cu}_{2} \mathrm{~N}_{4} \\
\mathrm{O}_{18} \mathrm{~S}_{2}\end{array}$ & \begin{tabular}{|l|}
$\mathrm{C}_{78} \mathrm{H}_{96} \mathrm{Mn}_{3} \mathrm{~N}_{6} \mathrm{O}_{12}$ \\
$1.05\left(\mathrm{H}_{2} \mathrm{O}\right)$
\end{tabular} & $\begin{array}{l}\mathrm{C}_{60} \mathrm{H}_{78} \mathrm{Co}_{3} \mathrm{~N}_{4} \mathrm{O}_{1} \\
2\end{array}$ \\
\hline MW & 219.28 & 639.30 & 645.96 & 617.51 & 816.25 & 1284.41 & \begin{tabular}{|l|}
1487.77 \\
\end{tabular} & 1224.05 \\
\hline Crystal system & \begin{tabular}{|l|} 
Trigonal \\
\end{tabular} & Triclinic & Triclinic & Triclinic & \begin{tabular}{|l} 
Triclinic \\
\end{tabular} & Monoclinic & \begin{tabular}{|l|} 
Trigonal \\
\end{tabular} & Orthorhombic \\
\hline Space group & $R \overline{3}$ & $P \overline{1}$ & $P \overline{1}$ & $P \overline{1}$ & $P \overline{1}$ & $C c$ & $R \overline{3}$ & Pccn \\
\hline$a / \AA$ & $33.0955(8)$ & $11.0894(7)$ & $11.0303(3)$ & $10.6575(8)$ & 9.9432(3) & $13.0413(2)$ & $15.6069(9)$ & $27.6849(9)$ \\
\hline$b / \AA$ & $33.0955(8)$ & 11.2694(7) & $11.2503(3)$ & 11.8208(9) & $19.4692(6)$ & $32.2971(4)$ & 15.6069(9) & $23.9258(5)$ \\
\hline$c / \AA$ & 11.8745(3) & 12.4577(9) & $12.6469(3)$ & 12.1533(9) & $20.9054(5)$ & $14.8434(2)$ & $29.9848(15)$ & $10.9518(2)$ \\
\hline$\alpha / \operatorname{deg}$. & 90 & 68.532(6) & 69.043(2) & $81.878(6)$ & $96.039(2)$ & 90 & 90 & 90 \\
\hline$\beta /$ deg. & 90 & \begin{tabular}{|l|}
$78.616(6)$ \\
\end{tabular} & 78.916(2) & 74.254(6) & 95.892(2) & $107.988(2)$ & 90 & 90 \\
\hline$\gamma /$ deg. & 120 & $87.720(5)$ & $87.910(2)$ & $78.403(6)$ & 99.024(2) & 90 & 120 & 90 \\
\hline$V / \AA^{3}$ & \begin{tabular}{|l|}
$11263.8(5)$ \\
\end{tabular} & \begin{tabular}{|l|}
$1419.44(16)$ \\
\end{tabular} & $1437.36(6)$ & 1437.42(19) & 3945.36(19) & 5946.39(14) & 6325.1(6) & 7254.3(3) \\
\hline$\overline{D_{c} / \mathrm{g} \mathrm{cm}^{-3}}$ & 1.164 & 1.496 & 1.493 & 1.427 & 1.374 & 1.435 & 1.172 & 1.121 \\
\hline $\bar{Z}$ & 36 & 2 & 2 & 2 & 4 & 4 & 3 & 4 \\
\hline $2 \theta_{\max } / \mathrm{deg}$. & 65 & 70 & 82 & 64 & 62 & 76 & 65 & 55 \\
\hline $\begin{array}{l}\mu(\mathrm{Mo}-K \alpha) / \\
\mathrm{mm}^{-1}\end{array}$ & 0.078 & 0.751 & 0.921 & 0.521 & 0.692 & 0.860 & 0.501 & 0.730 \\
\hline$T_{\min / \max }$ & $0.89 / 1.00$ & $0.808,0.903$ & $0.667,0.923$ & $0.921,0.977$ & $0.848,0.948$ & $0.803,0.876$ & $0.894,0.955$ & $0.846,0.944$ \\
\hline $\begin{array}{l}\text { Crystal } \\
\text { dimensions / } \\
\mathrm{mm}^{3}\end{array}$ & $\begin{array}{l}0.54 \times 0.29 \\
\times 0.17\end{array}$ & $\begin{array}{l}0.40 \times 0.33 \times \\
0.17\end{array}$ & $\begin{array}{l}0.65 \times 0.28 \times \\
0.10\end{array}$ & $\begin{array}{l}0.23 \times 0.17 \times \\
0.05\end{array}$ & $\begin{array}{l}0.32 \times 0.17 \times \\
0.08\end{array}$ & $\begin{array}{l}0.36 \times 0.32 \times \\
0.21\end{array}$ & $0.32 \times 0.21 \times 0.14$ & $\begin{array}{l}0.32 \times 0.22 \times \\
0.09\end{array}$ \\
\hline $\begin{array}{l}\text { Reflections } \\
\text { collected }\end{array}$ & 48373 & 20655 & 65578 & 16101 & 42028 & 114480 & 28986 & 82326 \\
\hline Unique $\left(R_{\text {int }}\right)$ & \begin{tabular}{|l|}
9062 \\
$(0.046)$
\end{tabular} & 11431(0.041) & $18607(0.032)$ & $9207(0.035)$ & $21693(0.054)$ & $\begin{array}{l}32310 \\
(0.041)\end{array}$ & $4887(0.106)$ & $8320(0.0650)$ \\
\hline$R I(I>2 \sigma(I))$ & 0.061 & 0.0391 & 0.0269 & 0.0546 & 0.0468 & 0.0417 & 0.0648 & 0.0841 \\
\hline$R 2$ (all data) & 0.164 & \begin{tabular}{|l|}
0.0743 \\
\end{tabular} & 0.0686 & 0.1142 & 0.0925 & 0.1095 & 0.1736 & 0.2451 \\
\hline $\begin{array}{l}\text { Largest peak, } \\
\text { hole e } . \AA^{-3}\end{array}$ & $\begin{array}{l}0.568,- \\
0.235\end{array}$ & $0.565,-0.507$ & $0.613,-0.419$ & $0.470,-0.380$ & $0.597,-0.624$ & $1.075,-1.004$ & $0.759,-0.737$ & $0.639,-0.738$ \\
\hline CCDC No. & \begin{tabular}{|l|}
1024905 \\
\end{tabular} & \begin{tabular}{|l|}
1024906 \\
\end{tabular} & \begin{tabular}{|l|}
1024907 \\
\end{tabular} & \begin{tabular}{|l|}
1024908 \\
\end{tabular} & \begin{tabular}{|l|}
1024909 \\
\end{tabular} & \begin{tabular}{|l|}
1024910 \\
\end{tabular} & \begin{tabular}{|l|}
1024911 \\
\end{tabular} & \begin{tabular}{|l|}
1024912 \\
\end{tabular} \\
\hline
\end{tabular}

